\title{
1 Benchmarking of techniques used to assess the freeze damage in potatoes
}

2 Piyush Kumar Jha ${ }^{\text {a, b, c, }}$, Kevin Vidot ${ }^{\text {c, d }}$, Epameinondas Xanthakis ${ }^{\text {e }}$, Xavier Falourd ${ }^{\text {c, d }}$, 3 Joran Fontaine a, b, c, Vanessa Jury a, b, c, Alain Le-Bail a, b, c

$4 \quad{ }^{a}$ ONIRIS, CS 82225, 44322 Nantes cedex 3, France

$5 \quad \mathrm{~b}$ UMR GEPEA CNRS 6144 - ONIRIS, 44322 Nantes cedex 3, France

$6 \quad$ c SFR IBSM 4204, 44316 Nantes, France

7 d UR 1268 Biopolymères Interactions Assemblages, INRA, 44316 Nantes, France

${ }^{\mathrm{e}}$ RISE Research Institutes of Sweden - Agrifood and Bioscience, Gothenburg 41276, Sweden

10

\section{Corresponding authors: Alain Le-Bail (alain.lebail@oniris-nantes.fr)}

\section{Abstract}

In this study, benchmarking of methods used for assessing freeze damage in potatoes was carried out. Initially, the samples were frozen by subjecting them to three different temperatures (i.e. at $-18{ }^{\circ} \mathrm{C},-30{ }^{\circ} \mathrm{C}$, and at $-74{ }^{\circ} \mathrm{C}$ ). Then, different analytical techniques comprising of focused methods (i.e. cryo-SEM, confocal laser scanning microscopy-CLSM) and global methods (i.e. texture analysis, low field nuclear magnetic resonance (NMR), exudate loss and colour change) were used to assess the impact of the freezing treatment from the different point of view addressed by each method. As a result, each of these methods were able to distinguish significantly fresh samples from the frozen-thawed samples. Focused methods like cryo-SEM and CLSM methods could differentiate the impact of all three different protocols. Meanwhile, texture analysis (including conventional method and novel method based on a touchless laser puff firmness tester), NMR and exudate loss could only determine the quality difference between $-18{ }^{\circ} \mathrm{C}$ and $-74{ }^{\circ} \mathrm{C}$ freezing conditions. Colour analysis was found as an inappropriate parameter for comparing the three freezing protocols. Among all analytical techniques, cryo-SEM provides the most authentic information about the product as the analysis is performed in frozen state, while for other techniques the product is thawed prior to analysis.

\section{Introduction}

Freezing is a preservation technique that has been used for ages for increasing the shelf life of food products. Compared to other long-term preservation methods, freezing technique causes 
less deterioration to nutrients and sensory properties in fruits and vegetables (Barbosa-

34 Cánovas, Altunakar \& Mejía-Lorío (2005). However, it can cause some irreversible damages such as texture loss, colour change, etc. Three main phenomena may describe freeze damage; the primary mechanical effect caused by the transition of water into ice, the biochemical effect caused by cryo-concentration and the secondary mechanical effect eventually caused by ice contraction after freezing (Reid, 1997; Shi, Datta, \& Mukherjee, 1999, 1998; Shi, Datta, \& Throop, 1998). The extent of freeze damage caused to the food products on thawing is greatly linked to the size and location of the ice crystals, which in turn is related to the applied freezing rate (Chevalier, Le Bail, \& Ghoul, 2000). Freeze damage can also be linked to the cryo-concentration effect; the aqueous solution present in the cells is exposed to a progressive concentration in solute caused by ice formation. The remaining aqueous phase which tends to become more and more concentrated can cause denaturation of the proteins and other organized biopolymers (i.e. cellulose based systems for fruits and vegetables), which in turn degrade their mechanical properties and by the way the overall texture of the tissue (Gao \& Critser, 2000; Lovelock, 1957; Reid, 1997). The mechanisms of freeze damage associated with cryo-concentration effect have been thoroughly discussed in a review article from Gao \& Critser (2000). Rapid freezing (high freezing rate) favours the genesis of fine ice crystals distributed uniformly within the product, thus reducing the dislocation of water from intra to the extra cellular spaces, resulting in higher water holding capacity upon thawing. In addition, the time of exposure to the highly concentrated aqueous solution caused by cryoconcentration is being reduced during rapid freezing, resulting to a lesser extend of the biochemical degradations (Delgado \& Sun, 2001; Fennema, 1966; Orlowska, Havet, \& LeBail, 2009; Sadot, Curet, Rouaud, Le-bail, \& Havet, 2017; Shi, Datta, \& Mukherjee, 1998; Singh \& Heldman, 2009). The result is reduced cell destruction and better quality attributes. However, two main disadvantages lie behind rapid freezing rates : (i) rapid freezing process requires a higher amount of energy, hence increases the consumed energy and the overall operating costs and (ii) the use of extremely high freezing rates such as cryogenic freezing, may lead to crack development in the samples and yield unexpectedly poor quality of the final product (secondary mechanical effect quoted above) (Shi, Datta, \& Mukherjee, 1999, 1998; Shi, Datta, \& Throop, 1998). On the contrary, at a slow freezing rate, intracellular water move to the extracellular domains (from the inside of the cell) and thus can result in greater ice crystal size (in the extracellular spaces) and also in a higher cell dehydration (Gao \& Critser, 2000; Mazur, 1984). Besides, slow freezing rate will also result in a prolonged exposition of 
Critser, 2000; Mazur, 1977, 1984). In fact, the formation of larger ice crystals along with volume shrinkage and long-term exposure to high solute concentrations would cause a higher destruction of cellular structure (high risk of punctured cell membrane/cell wall, collapsed cell structure and cell separation) (Chassagne-Berces et al., 2009; Chassagne-berces, Fonseca, Citeau, \& Marin, 2010; Gao \& Critser, 2000; Mazur, 1984). As an outcome, the leakage of the fluid from the cell will be higher and a product having a water-soaked appearance and mushy texture will be obtained. The last important parameter that may be responsible for quality losses of frozen foods is the storage conditions; time-temperature parameters, as well as temperature fluctuations, are also responsible for the quality loss.

The assessment of the quality of a frozen food product is obtained via analytical methods used to quantify the freeze damage. Broadly, these methods can be categorized as global methods and focused methods. The global methods provide quality information at a macro/meso level. In other terms, the quality information obtained using such methods is the average value from a whole sample or at least from a substantial piece of sample (several grams or several $\mathrm{cm}^{3}$ ). The global methods comprise of texture analysis, exudate loss measurement, solute diffusivity, impedancemetry, colour analysis, etc. While the focused methods provide quality information at a micro level (cell level or even at a lower scale such as ice crystal or water molecule scale). For instance, information about ice crystals size, cellular structure intactness, etc. can be obtained by using focused methods. Microstructures evaluation methods such as Scanning electron microscopy (SEM) (includes conventional SEM, environmental SEM (ESEM), and cryo-SEM), confocal laser scanning microscopy (CLSM), X-rays tomography, etc. fall under focused method. Low field nuclear magnetic resonance relaxometry (NMR) is at the same time a global and focused method as it embraces a sample of circa $1 \mathrm{~cm}^{3}$ scale and provides info at the level of water molecules (Jha et al., 2018).

In the literature, numerous benchmarking studies are available related to freezing effects on the quality parameters of the fruits and vegetables. However, no studies are available in the literature that benchmarks the techniques used to assess the freeze damage in fruits and vegetables.

This work was framed under the following objectives

i. To introduce new freeze damage assessment methods and check their efficiency in quantifying the freeze damage. 
ii. To benchmark the freeze damage methods (both conventional and novel) used for assessing the freeze damage in plant-based products with the intention to facilitate the researchers and industries to choose the appropriate method to assess the freeze damage.

The ultimate objective of this study is to provide a decision table which will allow to categorize the analytical techniques based on sensitivity, efficiency, accuracy, cost of operation, and ease of operation.

\section{Materials and methods}

\subsection{Product properties}

Potatoes (Solanum tuberosum L. cv. Innovator) were the food matrix chosen for this benchmarking study. McCain Foods (Harnes, France) kindly supplied us potato batch having uniform size and maturity. Two batches of potato were used for this test. The first batch of potato was used for NMR tests. In order to reduce the variability, for each freezing condition, samples intended for NMR test were taken from the same potato. Potatoes from the second batch were used for time-temperature history study and freeze damage assessment tests. The average moisture content of both batches was $75.70 \pm 1.40 \%$ (wet basis) (Note: the values of moisture content are presented here as mean \pm standard deviation. Similarly, the values for other parameters in the entire manuscript are expressed as mean \pm standard deviation).

\subsection{Sample preparations}

The sample size used to study the effect of conventional freezing processes on the quality parameters depended on the freeze damage assessment methods. For instance, to study the effect of freezing rates on freezing characteristics, texture, colour and drip loss, cuboids of potato $\left(1.3 \times 1.3 \times 1 \mathrm{~cm}^{3}-\right.$ length $\times$ height $\times$ width; weight $\left.1.95 \pm 0.5 \mathrm{~g}\right)$ were used. The potatoes were cut in cuboid shape using a dicer (Ibili Manage, Inc. Spain). The potato samples used for NMR relaxometry and cryo-SEM analysis were cylindrical in shape $(\varnothing=8 \mathrm{~mm}$ and $\mathrm{H}=10 \mathrm{~mm}$ ). For confocal laser scanning microscopy (CLSM) analysis, cylindrical potato samples $(\varnothing=8 \mathrm{~mm}$ and $H=5 \mathrm{~mm})$ were chosen. The samples were then immediately transferred into the freezer and were cooled from the ambient temperature to the desired temperature.

It is worth mentioning that during this study, one of our aims was to analyze the samples in its original state without causing any alterations to them, thus we had to vary sample size for potato according to the freeze damage assessment methods. For instance, NMR tube has an 
129 internal diameter of $1 \mathrm{~cm}$ and hence required sample having a diameter $<1 \mathrm{~cm}$. Also, another 130 requirement of NMR test is to have the NMR tube covered minimum up to $1 \mathrm{~cm}$ in height. 131 The cylindrical sample with a diameter of $8 \mathrm{~mm}$ and height of $1 \mathrm{~cm}$ perfectly matched both the 132 requirements. For cryo-SEM, sample size similar as NMR facilitated easy cutting of sample in 133 the frozen state and allowed the selection of the analyzed sample from nearly the same 134 location for each condition. For CLSM, small sample size helped the proper and fast staining 135 of the sample and facilitated the selection of the analyzed sample from the same location of 136 each matrix.

\section{$137 \quad$ 2.3. Freezing apparatus and freezing conditions}

138 Freezing of potatoes (unblanched) was performed at $-18{ }^{\circ} \mathrm{C}$ in a cold room, at $-30{ }^{\circ} \mathrm{C}$ and $1390.5 \mathrm{~m} / \mathrm{s}$ air velocity in an industrial batch freezer (MATAL, France), and at $-74{ }^{\circ} \mathrm{C}$ in an 140 ultra-low temperature freezer (TSE240V, Thermo Scientific, Marietta, Georgia, USA). The 141 three conditions will be referred to as slow freezing (SF), intermediate freezing (IF) and fast 142 freezing (FF) in further sections of the manuscript. Once frozen, the samples were packed in 143 the zip-lock and stored at $-40 \pm 2{ }^{\circ} \mathrm{C}(\approx$ for $2-3$ days $)$ until quality evaluation tests were 144 performed. The time-temperature profile during the freezing tests was studied by inserting a

145 K-type thermocouple at a geometric centre of the product. The (thermocouple) was calibrated 146 against a reference platinum probe (Comptoir Lyon Allemand - Lyon-France). During 147 measurements the temperature of the sample was recorded every $2 \mathrm{~s}$ with a data logger with 148 an accuracy of $\pm 0.1{ }^{\circ} \mathrm{C}$. For comparison purposes, temperature profiles from the initial 149 temperature $18{ }^{\circ} \mathrm{C}$ to $-18{ }^{\circ} \mathrm{C}$ were considered. The characteristic freezing time and overall 150 freezing time were determined using time-temperature data. The characteristic freezing time 151 was the measure of local freezing rate and it was defined as the time during which the 152 temperature at a particular point changed from the initial freezing point to a temperature at 153 which $80 \%$ of the water (at that point) was converted into ice. The temperature range 154 considered for the characteristic freezing time estimation was from -1 to $-7{ }^{\circ} \mathrm{C}$, similar 155 temperature range was used by $\mathrm{Li} \& \mathrm{Sun}$ (2002) for the determination of characteristic 156 freezing time during ultrasound assisted freezing of potatoes. The overall freezing time was 157 the time required to lower the temperature of the geometrical centre of the product from the 158 ambient temperature $\left(18{ }^{\circ} \mathrm{C}\right)$ in the present study) to a given temperature $\left(-18{ }^{\circ} \mathrm{C}\right)$. Samples 159 for quality analysis were frozen using the same procedure but without optical fibre inserted.

160 Each experiment was performed at a minimum of individual triplicates. 


\subsection{Thawing protocol}

162 The frozen potato samples were thawed at room temperature $\left(20 \pm 1^{\circ} \mathrm{C}\right)$ for $2 \mathrm{~h}$ in a zip-lock 163 bag ("static air thawing" method) before performing colour, drip loss, texture and solute 164 diffusion measurements. For NMR analysis the samples were thawed at $4{ }^{\circ} \mathrm{C}$ for $4 \mathrm{~h}$ in the 165 NMR tube.

\subsection{Colour analysis}

167 The colour of the potatoes was measured using a portable and handheld chroma meter CR400 (Konica Minolta, Inc. Japan). Using this equipment, the $L^{*}, a^{*}, b^{*}$ values for samples from each condition were obtained with high accuracy. The maximum value for $L^{*}$ is 100

170 (represents a perfectly white surface or a perfectly reflecting diffuser) and its minimum value 171 is 0 (represents perfectly black surface). The positive and negative a corresponds to red and 172 green colour. Similarly, positive and negative $b^{*}$ represents yellow and blue colour, 173 respectively. A single value for the colour difference was achieved by calculating the overall 174 colour difference $(\Delta \mathrm{E})$ value; it takes into account the differences between $\mathrm{L}^{*}, \mathrm{a}^{*}, \mathrm{~b}^{*}$ of the specimen (e.g. frozen-thawed sample) and reference (fresh sample), and it was calculated by

176 using Eq. (1) (Anon, 2018). The frozen samples were thawed before the colour measurements.

177 At least eight measurements were recorded for each freezing protocol.

$$
\Delta \mathrm{E}=\sqrt{\Delta \mathrm{L}^{*^{2}}+\Delta \mathrm{a}^{*^{2}}+\Delta \mathrm{b}^{*^{2}}}
$$

\subsection{Drip loss measurement}

180 The drip loss required great care in terms of manipulation. The mass differences that are being determined are usually small and it can be advantageous to use paper tissue to collect all the drip released by a sample. This requires the weight of the bag containing the sample, the initial mass of the tissue paper and all the final masses. There is also a risk of moisture condensation on the sample during frozen storage (if unpacked) or during the thawing process or even sample handling after thawing if their temperature is lower than the dew point temperature. The drip loss unit is very often given as g drip per g of sample. In most existing studies, drip losses are expressed as free drip; this means that drip the collected from the sample due to gravity forces and possible capillary interactions with the tissue paper. In some studies, the samples are compressed under selected stress (Jahncke, Baker, \& Regenstein, 1992) or after centrifugation for selected $g$ values under given times (Penny, 1975). In our 
194

study, the drip loss was determined based on the weight difference between frozen sample $\left(\mathrm{W}_{1}\right)$, and thawed sample $\left(\mathrm{W}_{2}\right)$. The drip loss (\%) was calculated using Eq. (2). At least 9 samples were analyzed for each freezing condition.

$$
\operatorname{Drip} \operatorname{Loss}(\%)=\frac{\mathrm{W}_{1}-\mathrm{W}_{2}}{\mathrm{~W}_{1}} \times 100
$$

\subsection{Texture analysis}

Texture analysis of food is often carried out using the TPA protocol (Texture Profile Analysis) proposed by Bourne (Bourne, 1968). Quite often, simple compression tests are used for frozen food aiming at determining the Young's Modulus (small deformation, typically $10 \%$ strain) and eventually the failure strain or stress. In our study, the frozen potato samples were thawed and compressed in a texture analyser (AMETEK, Lloyd Instruments, France) equipped with a $1000 \mathrm{~N}$ load cell and operating at a test speed of $50 \mathrm{~mm} / \mathrm{min}$ beyond failure point which was marked by a significant drop in the force reading (Figure 1). The compression test was performed using a $50 \mathrm{~mm}$ compression plate. A similar procedure was used by Khan \& Vincent $(1993,1996)$ for determining the failure stress, Young's Modulus, and failure strain of potato. Based on our preliminary trials and the results from Khan \& Vincent (1993) and Alvarez, et al. (2002), compression of the sample to 50\% strain was found more than sufficient to cause the failure of our sample (Figure 1). The maximum force exerted during the compression test was recorded as the firmness/hardness $(\mathrm{N})$ of the samples (Figure 1). Moreover, the stress vs. strain curves during compression tests were examined and Young's modulus (E) (the slope of the loading curve at the point of its highest gradient) was also acquired (Chassagne-Berces et al., 2009). All measurements were performed at $21 \pm 2{ }^{\circ} \mathrm{C}$. At least 12 samples were analyzed for each freezing condition.

\subsubsection{Laser-puff firmness tester}

A touchless laser-puff firmness tester which was designed and constructed in our lab (GEPEA lab, ONIRIS) was used for non-destructive measuring of the texture of fresh and frozenthawed potatoes (Figure 2). The firmness tester consists of the following components: a mean to generate impulsive jet of air; a nozzle (having a diameter of $0.004 \mathrm{~m}$ ) to direct the air onto the surface of the specimen under investigation; a deformation measurement unit containing a laser source to generate coherent source of light directed on the surface of the object impacted by the air jet, a detector of the light which is reflected from the specimen surface, and an 
analyzer to estimate the amount of deformation sustained by the product surface; a control panel to change the pressure value and an appropriate software (developed in our lab) to execute the test. Based on the preliminary trials, for measuring the firmness of frozen-thawed potatoes, the air nozzle was located at $10 \mathrm{~mm}$ from the food surface and an air pressure of $5 \times$ $10^{5} \mathrm{~Pa}$ and air jet exposure time of $100 \mathrm{~ms}$ were found most appropriate. The estimated pressure exerted onto the food surface was in the range of $3.32 \times 10^{5} \mathrm{~Pa}$ assuming a surface of $1.256 \times 10^{-5} \mathrm{~m}^{2}$ impacted by the air jet. Prussia, Astleford, Hewlett, \& Hung (1994) used impact pressure of $3.10 \times 10^{5} \mathrm{~Pa}(45 \mathrm{psia})$ in order to determine the firmness of potato. Similar to the authors, Hung, McWatters, \& Prussia (1998) who used the same exposure time to determine the firmness of peaches.

The sample was placed on the sample platform below the air delivery nozzle and the position of sample was adjusted using a positioner in order to ensure (i) the air jet and the laser hits the same point on the sample and (ii) the distance between end of the nozzle and the sample surface is same for all trials. Subsequently, by using the software air jet was directed on the sample and the deformation was measured. The software yielded deformation results in volts (Figure 3). The maximum deformation can be referred to as the difference between the highest initial value and lowest value recorded by the deformation unit during the test. The conversion of volts to $\mathrm{mm}$ (millimeter) based unit was made by multiplying with a conversion factor (in the present case, volt value was multiplied by 2 to obtain final value in $\mathrm{mm}$ ). The final deformation value was an average of sixteen measurements.

\subsection{Microstructure examination}

\subsubsection{Cryo-SEM analysis}

243 Cryo-SEM analysis is a very specific technique which requires very careful and proper sample preparation. A thin specimen of slab shape was cut from a given location of the frozen food using a sharp scalpel. In our case, the central section of the frozen potato samples was selected for collecting the sample. Also, in the case of structured tissue, given shape must be provided to the sample to identify a given orientation; for example, in the case of a muscle, the longer section of sample is usually longitudinal to the fibers in order to be able to do cut view either parallel or perpendicular to the fibers. In the case of a vegetal tissue has no major orientation so special care was taken mainly for the location, shape and size of the sample. It was fixed into the groove notched in a copper sample holder (10 mm diam. $10 \mathrm{~mm}$ height) using an OCT (optimal cutting temperature) compound (Tissue-Tek, Sakura, Finetek, USA). 
An important technical issue lies in preventing any thawing of sample when the sample is contacted onto the sample order. To overcome this difficulty, the following protocol was used. All manipulations were done in a cold box filled with $\mathrm{CO}_{2}$ sticks $\left(-78.5^{\circ} \mathrm{C}\right)$ in order to condition the sample which was kept in this ambiance. The sample holder was refreshed down to around $0{ }^{\circ} \mathrm{C}$ by contacting a $\mathrm{CO}_{2}$ stick. Then a small amount of OCT was installed in the groove of the sample holder. Then, at the same time, the sample holder was contacted onto a $\mathrm{CO}_{2}$ stick meanwhile the frozen sample was contacted to the OCT located in the groove. Within less than a few seconds, the sample was fixed onto the sample holder thanks to the freezing of the OCT. The very high thermal diffusivity of the copper material (sample holder) compared to the frozen sample ensures that the sample will not undergo any thawing when the sample is contacted to the sample holder. The sample was left for $2 \mathrm{~min}$ in a box filled with dry $\mathrm{CO}_{2}$ to harden the OCT compound. After that, the sample was loaded onto a precooled copper specimen stub (in liquid $\mathrm{N}_{2}$ ) and was quickly transferred in the cryo-preparation chamber of the cryo-SEM (LS10, ZEISS EVO, Germany) maintained under vacuum at - 80 ${ }^{\circ} \mathrm{C}$, where it was cryo-fractured using a precooled sharp knife mounted inside the chamber. The fractured sample was etched in the preparation chamber for about 5 to $10 \mathrm{~min}$ to expose the subsurface information in order to allow a partial sublimation of the ice crystals. The etching time required adjustment depending on the size of the sample, the pressure level and the type of tissue. The sample was finally coated with a thin conducting layer of gold $(5 \mathrm{~nm})$ in the cryo-preparation chamber and then was transferred to the cold stage in the cryo-SEM (maintained at $-80{ }^{\circ} \mathrm{C}$ ) where microstructural observation was performed. The fractured surfaces of potatoes were examined with an accelerating voltage of $11 \mathrm{kV}$. An illustration of the sample preparation steps is presented in Figure 4. It is worth mentioning that all the samples prepared for cryo-SEM analysis after the different freezing conditions acquired from the same potato.

\subsubsection{Confocal laser scanning microscopy (CLSM)}

The confocal laser scanning microscopy was also used for potatoes samples. Figure 5 provides a brief description of the protocol followed to prepare potatoes for the CLSM observations. The CLSM was performed using an Eclipse Ti inverted microscope (Nikon Ti A1, Japan). For each freezing condition, independent experiments were performed in triplicates.

It is worth noticing that the acridine orange (used for this study) is well known to be a 
metachromic dye, especially for staining DNA and RNA. Such dye is able to give

286 fluorescence with emissions wavelength depended on its interaction with chemical functions, charge or geometry of a compound. The acridine orange was chosen here as a dye able to stain simultaneously the different cell layers of the fruits as it has been widely applied for fluorescent staining of plant tissue with a high fluorescence emission. The maximum emission wavelength of this dye is $500-530 \mathrm{~nm}$ and excitation occurs at about $488 \mathrm{~nm}$.

\subsection{NMR relaxometry}

292 For all the freezing protocols, NMR tests were performed for samples in frozen state (at -20 $293{ }^{\circ} \mathrm{C}$ ) and frozen-thawed state $\left(\right.$ at $4{ }^{\circ} \mathrm{C}$ ). Initially, the frozen samples were placed in the NMR 294 tube $(\varnothing=10 \mathrm{~mm})$ precooled to $-20{ }^{\circ} \mathrm{C}$. Then the tube was quickly placed in the 295 spectrometer (maintained at $-20{ }^{\circ} \mathrm{C}$ ) and left for $10 \mathrm{~min}$ to ensure that the samples were at $296-20{ }^{\circ} \mathrm{C}$ at the beginning of NMR test at a negative temperature. Upon completion of NMR 297 tests in frozen condition, the same samples were thawed (at $4{ }^{\circ} \mathrm{C}$ for $4 \mathrm{~h}$ ) and then NMR tests on frozen-thawed samples (at $4{ }^{\circ} \mathrm{C}$ ) were carried out. In order to compare the damage caused 299 by different freezing procedures, the NMR measurements of fresh samples were performed at $300 \quad 4{ }^{\circ} \mathrm{C}$ and were compared with results obtained for frozen-thawed samples obtained under 301 various freezing protocols. The Minispec mq20 spectrometer (Bruker) at $0.47 \mathrm{~T}(20 \mathrm{MHz}$ 302 proton resonance frequency) equipped with a thermostated $\left( \pm 0.1{ }^{\circ} \mathrm{C}\right){ }^{1} \mathrm{H}$ probe was used for 303 NMR analysis. Triplicates were performed for each freezing condition of potato.

304 In the present study, $T_{2}$ (transverse) relaxation time of protons and their respective population 305 in the product were evaluated. The $T_{2}$ distributions were determined using a 306 Carr-Purcell-Meiboom-Gill (CPMG) sequence. For the NMR test at frozen and frozen307 thawed state, the $180^{\circ}$ pulse separation was 0.04 and $0.1 \mathrm{~ms}, 2000$ and 10000 even echoes 308 were collected, and the 1024 and 256 scans were acquired with a recycle delay of 1 and $5 \mathrm{~s}$ 309 resulting in a total acquisition time of about 20 and 40 min respectively.

310 An inverse Laplace transformation (ILT) was applied to convert the relaxation signal into a 311 continuous distribution of $T_{2}$ relaxation components. For this purpose, a numerical 312 optimization method was used by including non-negativity constraints and L1 regularization 313 and by applying a convex optimization solver primal-dual interior method for convex 314 objectives (PDCO).

\subsection{Statistical analysis}


316 One-way ANOVA (analysis of variance) was used to determine any significant difference (in 317 terms of freezing and quality characteristics) among the freezing conditions. Duncan's 318 multiple range test was performed to determine differences between the means $(p<0.05)$.

\section{3. Results and discussion}

\subsection{Effect of different freezing rates on temperature history}

The representative temperature histories of potatoes frozen under the different freezing conditions are presented in Figure 6. The SF process yielded freezing curves having three stages i.e. the supercooling, nucleation, and phase change. Meanwhile, intermediate freezing (IF) exhibited only two stages (i.e. nucleation and phase change stages) and fast freezing (FF) showed only one stage (i.e. phase change state) in Figure 6. SF condition gave a degree of supercooling of $0.15 \pm 0.07{ }^{\circ} \mathrm{C}$, while no supercooling curve was observed for the other two freezing conditions. Similar freezing curves lacking obvious supercooling at higher freezing rates (at $-80{ }^{\circ} \mathrm{C}$ and liquid nitrogen immersion freezing) were also obtained by Cao et al. (2018) during freezing of blueberries. It was inferred by them that at a faster freezing rate the supercooled state might be unstable or lack persistence. The initial freezing point for SF and IF condition was recorded as $-0.3 \pm 0.14$ and $-0.73 \pm 0.06{ }^{\circ} \mathrm{C}$ (Table 1). It seems that a slight depression in freezing point happened upon increasing the freezing rate. For FF condition, it was hard to detect the initial freezing point due to a rapid decline in the temperature during the freezing process. However, more replications could be helpful to be conducted prior to the confirmation of this outcome. Recently, Cao et al. (2018) also reported slight decrease (but not significant) in the initial freezing temperature of blueberries when the freezing rate was increased from $0.023{ }^{\circ} \mathrm{C} / \mathrm{s}\left(\right.$ at $-20{ }^{\circ} \mathrm{C}$ ) to $0.049{ }^{\circ} \mathrm{C} / \mathrm{s}$ (at $-40{ }^{\circ} \mathrm{C}$ ) or $0.11^{\circ} \mathrm{C} / \mathrm{s}$ (at $-80{ }^{\circ} \mathrm{C}$ ) or $0.76{ }^{\circ} \mathrm{C} / \mathrm{s}$ (liquid nitrogen immersion freezing). The initial freezing point of blueberries at $0.023,0.049,0.11$, and $0.76{ }^{\circ} \mathrm{C} / \mathrm{s}$ rates were recorded as $-2.67 \pm 0.32{ }^{\circ} \mathrm{C}$, $-3.23 \pm 0.12{ }^{\circ} \mathrm{C},-3.53 \pm 0.35{ }^{\circ} \mathrm{C}$ and $-3.36 \pm 0.60{ }^{\circ} \mathrm{C}$ respectively (Cao et al., 2018). Among other freezing parameters being studied, the characteristic freezing time was found to be the shortest for FF condition $(8.52 \pm 1.53 \mathrm{~min})$, followed by IF and SF condition $(17.18 \pm 0.79 \mathrm{~min}$ and $29.12 \pm 3.94 \mathrm{~min}$ respectively) (Table 1$)$. The time spent in this zone is very crucial as it determines the quality of the final product. From the perspective of higher quality preservation, a shorter width of this zone is desired. Similar to characteristic freezing time, the overall freezing time and the overall freezing rate also exhibited a similar trend.

\subsection{Texture analysis}




\subsubsection{Conventional method}

349 The confined compression test was the conventional method used to determine the texture of 350 potatoes. The hardness and Young's modulus values of fresh and thawed sample (from 351 different freezing conditions) are shown in Table 2. The values of fresh samples were 352 significantly different $(\mathrm{p}<0.05)$ compared with those of the frozen-thawed samples. FF 353 process caused less decay in hardness value $(\approx 50 \%)$ than IF process $(\approx 62 \%)$ or SF process $354(\approx 74 \%)$. However, significant differences in hardness values were observed only between SF 355 and FF samples. Young's modulus values exhibit a similar tendency as hardness values in 356 Table 2.

357 Khan \& Vincent (1996) reported that compressive stiffness of potato less degraded when 358 freezing was performed at a higher freezing rate $\left(10^{\circ} \mathrm{C} / \mathrm{min}\right)$ compared to slow freezing rate 359 ( $\left(1^{\circ} \mathrm{C} / \mathrm{min}\right)$. According to Mazur (1984) and Chassagne-Berces, Fonseca, et al. (2010), lower 360 dehydration associated with small ice crystals induced less breakage of cell walls, and hence, 361 better texture preservation was achieved at higher freezing rates when compared to the slow 362 freezing rate. The high freezing rates also decrease the collapse of cell walls and generate less 363 intercellular spaces, and hence result in better texture preservation (Chassagne-Berces et al., 364 2009). Besides, Phinney, Frelka, Wickramasinghe, \& Heldman (2017) reported that the 365 extent of texture loss of potato depends on the freezing time. It was found that the hardness of 366 thawed potato reached a maximum value when the freezing time decreased dramatically up to $3671000 \mathrm{~s}$. Further, increase in freezing time beyond $1000 \mathrm{~s}$ to around $5000 \mathrm{~s}$ did not cause any 368 further texture loss in their case. Van Buggenhout et al. (2006) evaluated the effect of three 369 different freezing conditions i.e. slow freezing (freezing time $\left(f_{t}\right)=300 \mathrm{~min}$ ), rapid freezing $\left(f_{t}\right.$ $370=40 \mathrm{~min})$ ) and cryogenic freezing $\left(f_{t}=10 \mathrm{~min}\right)$ ) on the hardness retention of thawed carrots.

371 They reported that rapid and cryogenic freezing condition had a higher hardness retention 372 than the slow freezing condition.

\section{3.2.2. Laser-Puff firmness tester}

374 Laser-Puff firmness tester allows rapid and non-destructive texture analysis of the food 375 products (Hung et al., 1998; McGlone \& Jordan, 2000; Prussia et al., 1994). An attempt was 376 made to use this method, to the best of our knowledge for the first time, for measuring the 377 texture of frozen-thawed fruits and vegetables. In this section, the results from laser-puff 378 firmness analysis of potato will be presented and discussed. The deformation curves and 379 deformation values obtained during laser-puff firmness test of fresh and frozen-thawed 
potatoes (under different freezing rates) are shown in Figure 7. The fresh samples had 381 significantly $(\mathrm{p}<0.05)$ lower deformation value than all frozen-thawed samples (Figure $7 b)$. 382 As expected, SF samples suffered the highest deformation during the tests. The deformation occurred at IF samples was less than SF samples, but greater than the FF samples. However, the deformation values of IF samples were not significantly different $(p>0.05)$ from the values of SF and FF samples. The FF sample showed lower deformation than the other conditions, and those values were found to be significantly lower than SF, but not significantly different from IF values. The obtained results (in terms of deformation) are coherent with those obtained by the classical method (discussed above). In conclusion, this method could distinguish fresh and frozen-thawed samples, but had limited capability to differentiate the tested freezing conditions.

\subsection{NMR relaxometry}

392 NMR tests were performed for the samples in frozen $\left(\right.$ at $-20{ }^{\circ} \mathrm{C}$ ) and frozen-thawed states (at $3934{ }^{\circ} \mathrm{C}$ ) after being frozen under the different freezing conditions. Figure 8 shows the results 394 from NMR relaxometry of potato in a frozen state (at $-20{ }^{\circ} \mathrm{C}$ ). The relaxation peaks, $T_{2}^{*}$ 395 (including magnetic field inhomogeneities) and $T_{2}$ of frozen samples provide information 396 about the structure of the samples and about the unfrozen water at $-20{ }^{\circ} \mathrm{C}$ (Figure 8 ). $T_{2 \alpha}^{*}$ is 397 the relaxation peak of protons associated with the macromolecules. $T_{2 \beta}^{*}, T_{2 \gamma}$, and $T_{2 \delta}$ are the 398 relaxation peaks associated with the protons of unfrozen water (Foucat \& Lahaye, 2014; 399 Luyts et al., 2013). Results showed that the $T_{2 \alpha}^{*}$ values (relaxation time and proton population) 400 for all freezing conditions were similar, which indicated that the different freezing protocols 401 didn't influence differently the systems at a macromolecular level (Figure 8a). Similarly, $T_{2 \beta}^{*}$ values were not significantly different among the different freezing conditions (Figure 8a). If

403 we follow the hypothesis that the faster the freezing process is the less is the destruction it 404 imparts, the values of relaxation peak components of non-freezable water $\left(T_{2 \gamma}\right.$ and $\left.T_{2 \delta}\right)$ associated with the samples frozen quickly provide an evidence of better preservation of structures. Only samples that were frozen slowly (at $-18{ }^{\circ} \mathrm{C}$ ) showed different values for

407 these relaxation peak components (Figure $8 \mathrm{a}$ and $\mathrm{b}$ ). It was observed that $T_{2 \gamma}$ component 408 values (relaxation time and proton population) for IF and FF conditions were not significantly 409 different $(\mathrm{p}>0.05)$ between each other, meanwhile, these values were significantly different 410 ( $\mathrm{p}<0.05)$ with that obtained for SF condition. The lowest value of $T_{2 \gamma}$ time observed for slow 411 freezing $(0.72 \mathrm{~ms}$ instead of around $0.80 \mathrm{~ms}$ for the other freezing conditions) can be 
explained by a greater destruction followed by a diffusion of "solutes" inducing a relative 413 increase in viscosity (Lahaye, Falourd, Limami, \& Foucat, 2015). The $T_{2 \delta}$ component 414 relaxation times for all freezing conditions were not different from each other. But, the $415 T_{2 \delta}$ component proton population was significantly lower $(\mathrm{p}<0.05)$ for SF compared to the 416 other conditions. This seemed to indicate the loss of fluid from the respective water 417 compartment due to greater damage occurred during SF process. No significant difference (p $418>0.05$ ) (with respect to $T_{2 \delta}$ component proton population) was observed among IF and FF 419 samples.

420 Figure 9 represents the $T_{2}$ peaks of fresh and frozen-thawed samples at $4{ }^{\circ} \mathrm{C}$. With regard to 421 fresh samples, the distribution of $T_{2}$ relaxation peak has five components $\left(T_{2 a}, T_{2 b}, T_{2 c}, T_{2 d} \&\right.$ $422 T_{2 e}$ ), whose values averages are in good agreement with the literature data (Rutledge, Rene, 423 Hills, \& Foucat, 1994). Based on these data, an allocation of different components of $T_{2}$ have 424 been proposed: $T_{2 a}$ and $T_{2 b}$ are the relaxation peaks associated with the water present in the 425 cell walls and the vacuolar membrane. $T_{2 c}$ is the relaxation peak of water in starch grains. $T_{2 d}$ 426 and $T_{2 e}$ are the relaxation peaks of water in the non-starch vacuoles, the nucleus and the 427 cytoplasm (Rutledge et al., 1994). The measurement of the $T_{2}$ components values (relaxation 428 time and proton population) of the samples after thawing makes it possible to observe the 429 influence of different freezing protocols on the mobility of the water compared with the fresh 430 samples. It can be seen that the freezing-thawing process affects the resolution of the $T_{2}$ 431 distribution peaks (Figure 9). For instance, the $T_{2 c}$ and $T_{2 d}$ components which were 432 distinctively visible in the fresh sample could no longer be differentiated in the frozen-thawed 433 sample. Apart from this, $T_{2 d}$ and $T_{2 e}$ times of fresh potato decreased upon freezing-thawing.

434 Among the different freezing conditions used in this study, only FF (at $-74{ }^{\circ} \mathrm{C}$ ) preserved $T_{2}$ 435 components distributions with good resolution over the entire time range studied. Four $T_{2}$ 436 components were characterized for FF (against five for fresh samples), meanwhile, for IF and 437 SF conditions, three and two $T_{2}$ components could only be characterized. For all freezing 438 conditions, the mobility of water associated with non-starch vacuoles, nuclei and cytoplasm $439\left(T_{2 d}\right.$ and $\left.T_{2 e}\right)$ decreased. This reflects a reorganization of the fluids following a partial rupture 440 of the cellular structures (Lahaye et al., 2015) irrespective of the freezing speed. Compared to 441 fresh sample, the decrease in $T_{2 e}$ time was lower for FF process $(\approx 46 \%)$ and was followed by $442 \mathrm{SF}(\approx 53 \%)$ and $\mathrm{IF}(\approx 54 \%)$ process. However, no significant difference among freezing 443 processes (in terms of $T_{2 e}$ time) was observed. $T_{2 e}$ component proton population data reveal 
that FF and IF samples had similar values $(\mathrm{p}>0.05)$ as the fresh sample, while it significantly decreased $(\mathrm{p}<0.05)$ in the case of SF samples. This decrease was followed by an increase in proton population of the consecutive peak in the $T_{2}$ distribution curve for SF samples (Figure $9 b)$, depicting the transfer of water between two compartments which might have probably happened due to the breakdown of vacuolar membrane. However, no such trend was observed for other freezing conditions (Figure $9 \mathrm{c}$ and d). The $T_{2}$ component values (relaxation time and proton proportion) adjacent to the $T_{2 e}$ for SF samples was significantly different $(\mathrm{p}<0.05)$ from those of FF and IF conditions. The $T_{2 a}$ and $T_{2 b}$ components of FF samples had similar relaxation times as the fresh samples, illustrating the overall better preservation of membranes and walls (despite a reorganization at the level of populations). IF also fairly maintained the $T_{2 b}$ component values and they were found to be similar to the fresh sample. Due to poor resolution, it was difficult to extract $T_{2 a}$ component value for IF samples. $T_{2 a}$ and $T_{2 b}$ component values for SF sample also could not be resolved due to the poor resolution of the peak.

Cao et al. (2018) used $T_{2}$ time of water proton to differentiate fresh blueberries from frozenthawed blueberries. They found that the freezing-thawing process caused a reduction in $T_{2}$ time of vacuole, cell wall, cytoplasm and extracellular water compared to the fresh sample. With respect to the proton population of different compartments, it was observed that freezing and thawing did not cause any alteration in the proton population of different compartments compared to a fresh samples. Moreover, they also used $T_{2}$ relaxation peak data to distinguish different freezing conditions (i.e. freezing at $-20,-40,-80{ }^{\circ} \mathrm{C}$ and freezing by immersing in liquid nitrogen). It was reported that among all freezing conditions, - $80{ }^{\circ} \mathrm{C}$ freezing conditions better maintained $T_{2}$ time of vacuole $(\mathrm{p}<0.05)$ depicting better protection to the vacuole membrane. Unlike them, we did not observe any significant difference among the freezing trials with respect to the relaxation times of thawed samples frozen by different methods, however, we could observe a significant differences between FF, IF and SF conditions with respect to the proton population of $T_{2}$ peaks. The proton population data

471 (associated with $T_{2}$ times) was used by Zhang et al. (2018) to study the effect of state/phase 472 transition on water mobility in frozen mango during 4-week storage.

\subsection{Drip loss}

Drip loss is one of the commonly and widely used methods to evaluate the freeze damage in

475 frozen products (especially in meat, fish, fruits and vegetable matrices). This method 
estimates the freeze damage at a global level, or in other terms, provides an average value of freeze damage of a product. In this section the impact of the studied freezing conditions on the exudate loss from the product will be presented and discussed. Figure 10 shows the dependence of drip loss on freezing rate. The results reveal that drip loss decreased slightly when freezing rate was increased, however, significant difference was observed only between samples that were frozen under FF and SF conditions. IF samples were not significantly different $(p>0.05)$ compared to the samples of the other two freezing rates. The drip loss results exhibited similar trends to those of $T_{2 e}$ component proton population from NMR that showed that the application of $-18{ }^{\circ} \mathrm{C}$ freezing protocol maintained less the intracellular water content. This result may be attributed to a better preservation of the intracellular water and to a lower damage of the pectocellulosic walls from the faster freezing rates. As a result, this method was able to detect the differences between the selected freezing rates. The water holding capacity of the frozen sample is linked to the size and location of ice crystals as well as the thawing rate (Van Buggenhout, Messagie, et al., 2006). The formation of large ice crystals in the cellular matrix can affect the water holding capacity of a cellular matrix in two ways: (i) large ice crystals genesis during freezing can damage the cell membrane due to mechanical effects, to cryo-concentration phenomena and shrinkage effects (particularly during slow freezing rates) which in turn, will promote loss of mass during thawing (Bevilacqua, Zaritzky, \& Calvelo, 1979; Delgado \& Sun, 2001; Sadot et al., 2017) and (ii) higher drip loss may occur due to the formation of bigger ice crystals which correspond to smaller specific surface area. This fact is associated with water re-absorption decrease during thawing (Bevilacqua et al., 1979; Sadot et al., 2017). Charoenrein \& Owcharoen (2016) and Fuchigami, Hyakumoto, \& Miyazaki (1995) observed decrease in exudate loss with increasing freezing rates in frozen mangoes and carrots.

\subsection{Colour}

Freezing-thawing process significantly $(\mathrm{p}<0.05)$ affected the colour parameters $\left(\mathrm{L}^{*}, \mathrm{a}^{*}\right.$, and $b^{*}$ values) of the unblanched potatoes Figure 11. The $L^{*}$ value (or lightness) and $b^{*}$ value (or yellowness) decreased, while the $\mathrm{a}^{*}$ value (redness) increased for potatoes after freezingthawing (Figure 11a, b and c). These results are in agreement with the previously reported study on freezing-thawing of unblanched potatoes (Koch et al., 1996). The colour change during the freezing-thawing process of unblanched potato has been attributed to the browning reaction that generally happens due to enzymatic activity during thawing process (Cano, 1996; Koch et al., 1996). The freezing rates had little effect on the colour parameters of 
potatoes. Interestingly, it was found that FF process increased the redness value of potatoes

510 significantly $(\mathrm{p}<0.05)$ than compared to SF process. Chassagne-berces, Fonseca, et al.

511 (2010) reported that freezing at $-80{ }^{\circ} \mathrm{C}$ increased the redness value of Golden Delicious apple

512 compared to the one frozen at $-20{ }^{\circ} \mathrm{C}$. The redness value of IF samples was not significantly

513 different compared with those frozen under FF and SF conditions. No significant differences

514 for rest of the colour parameters $\left(\mathrm{L}^{*}\right.$ value, $\mathrm{b}^{*}$ value and $\left.\Delta \mathrm{E}\right)$ were observed among the 515 freezing protocols.

\subsection{Microstructure analysis}

517 3.6.1. Cryo-SEM analysis

518 Scanning electron microscopy permits to obtain very high-quality images of a food matrix 519 microstructure. With respect to the frozen cellular matrices, micrographs acquired using SEM 520 (especially the cryo-SEM) provide important details about ice and cell morphology (shape of 521 the cell and the integrity of pectocellulosic walls). To the best of our knowledge, for the first time, cryo-SEM was used to compare the changes occurring to the microstructure of potato at different freezing rates. Figure 12 illustrates the SEM images of fresh and frozen potatoes.

524 The images of fresh and frozen potato were obtained using an environmental SEM (E-SEM) 525 and cryo-SEM, respectively. It can be seen in the figure that the fresh potato has polyhedral 526 shape cells with starch embedded in it. The microstructure morphology upon freezing 527 depended highly on the freezing rate being applied. The SF process not only created bigger ice crystals in the cells but also caused the highest damage to the cellular structure. The cells were highly distorted (deformed cells with broken and irregular cell wall structure) under SF conditions. The IF process produced smaller ice crystals and maintained the cell wall integrity better than the SF conditions. However, some cells lost their polyhedral shape and turned almost into round shape when freezing was performed at IF conditions (cells pointed by the orange arrow in Figure 12e and Figure 12f). The FF process yielded smallest ice crystals compared to other freezing processes. Moreover, it can also be observed that the cellular structure (in terms of cell shape i.e. polyhedral shape and cell wall integrity) was maintained well. Similar to the authors, Bomben \& King (1982), Chassagne-Berces et al. (2009) and

537 Chassagne-Berces, Fonseca, et al. (2010) cryo-SEM imaging could differentiate the apples 538 frozen by different freezing conditions based on microstructure. Moreover, they also observed 539 that slow freezing process (e.g. freezing at $-20{ }^{\circ} \mathrm{C}$ or $0.4 \mathrm{~K} / \mathrm{min}$ ) altered the shape of the cell 540 more than the fast freezing processes (e.g. freezing at $-80{ }^{\circ} \mathrm{C}$ or $450 \mathrm{~K} / \mathrm{min}$ or by liquid 541 nitrogen immersion freezing). The calculations for ice crystals size were not made as it was 
542 difficult to locate the boundary of the ice crystals. Moreover, the ice crystals had a 3D 543 structure and if the calculation were made, we could get only 2D information, this would have 544 led to an inaccurate estimation of the size of the ice crystals. Chassagne-Berces et al. (2009) 545 quantified the size of ice crystals formed at different freezing protocols (at $-20{ }^{\circ} \mathrm{C},-80{ }^{\circ} \mathrm{C}$ 546 and by immersion in liquid nitrogen) from the cryo-SEM images using gray level 547 granulometry based on mathematical morphology. They reported that the size of ice crystals 548 was between 10 and $30 \mu \mathrm{m}$ after freezing at $-20{ }^{\circ} \mathrm{C}$ and below $5 \mu \mathrm{m}$ for faster freezing at $549-80{ }^{\circ} \mathrm{C}$ and by immersion in liquid nitrogen conditions. Since we were not able to quantify the size of ice crystals, a direct comparison with their results remained difficult.

\subsubsection{CLSM analysis}

552 CLSM images of fresh and frozen-thawed potatoes are presented in Figure 13. This method 553 provides information about the status of the cell such as the shape of cells and integrity of the 554 cell wall. Compared to the fresh sample, the cells were highly disorganised and distorted in 555 SF samples. The altered shape of the cells and damaged cell wall structures in the slowly frozen sample can be observed in the CLSM images (Figure 13). The buckled and folded cell wall structure in SF samples indicated a major dehydration related damage that generally happens at lower freezing rates (Chassagne-Berces et al., 2009; Gao \& Critser, 2000; Mazur, 1977, 1984). IF process affected the cell shape as cell walls were found slightly distorted, while IF seemed to have fairly preserved the integrity of the cellular structure and avoid cell wall rupture as observed by SF. Moreover, extracellular spaces that can be generated due to the freezing-thawing process were observed in IF samples (Figure 13c), while it was missing in FF samples (Figure 13d). It can be seen (Figure 13c and Figure 14c) that these gaps were adjacent to the shrunk cells, which clearly indicates the dislocation of water from the inner of the cell to the extracellular space. It was difficult to distinguish freezing-thawing induced gaps 566 between the cells in SF sample as the structure was completely destroyed. FF condition 567 helped to preserve the original shape and integrity of the cellular structure. The results from 568 CLSM (in terms of cell morphology) were coherent with the results from cryo-SEM. Charoenrein \& Owcharoen (2016) used CLSM to study the effect of freezing rates and freezethaw cycles on the cellular structure of mangoes. Using this method, they were able to observe the freezing-thawing related degradation of cellular structure. Moreover, based on

572 CLSM images, they were able to discriminate the different freezing protocols (i.e. freezing at $573-80,-40$ and $\left.-20{ }^{\circ} \mathrm{C}\right)$. For instance, CLSM micrographs depicted that cells observed after

574 fast freezing (at $-80{ }^{\circ} \mathrm{C}$ ) and thawing suffered a minimal amount of degradation; the cells 
were still round and similar to cells from fresh tissues. The IF frozen (at $-40{ }^{\circ} \mathrm{C}$ )-thawed sample showed a slightly flat cellular structure, while the slow frozen (at $-20{ }^{\circ} \mathrm{C}$ )-thawed mangoes exhibited larger changes. The cells of the slowly frozen samples lacked uniformity and some intercellular spaces were also observed in slowly frozen tissues. Sirijariyawat, Charoenrein, \& Barrett (2012) used CLSM to study the change in cellular morphology in mangoes upon freezing-thawing. They reported that freezing (at $-50^{\circ} \mathrm{C}$ ) followed by storage (at $-20{ }^{\circ} \mathrm{C}$ chest freezer for 14 days) and thawing (at $4{ }^{\circ} \mathrm{C}$ for $2 \mathrm{~h}$ and kept at $25{ }^{\circ} \mathrm{C}$ for 30 min prior to analysis) of mango samples transformed the well-defined circular to elliptical regular cells of fresh sample to irregular shaped cells with disintegrated cell wall.

\section{Conclusions}

In this study, potato samples were frozen under different freezing regimes and their quality were evaluated using different techniques. The slowly frozen $\left(-18{ }^{\circ} \mathrm{C}\right)$ potatoes exhibited supercooling during freezing while no supercooling was noticed for other freezing conditions (i.e. $-30{ }^{\circ} \mathrm{C}$ - intermediate freezing process and $-74{ }^{\circ} \mathrm{C}$ - fast freezing process). The initial freezing point (initial freezing temperature) could be detected for slow freezing and intermediate freezing conditions, while it was hard to detect the initial freezing point for the fast freezing condition. The initial freezing point temperature data for slow freezing and intermediate freezing conditions revealed that a depression in freezing point occurred when freezing rate was increased. The slow freezing process resulted in coarser ice crystals and also caused the highest damage to the cellular structure. The cells were highly distorted (deformed cells with buckled and folded cell wall structure) when the slow freezing condition was used. Intermediate freezing rate process led to relatively fine ice crystals compared to slow freezing process. Although IF process led to greater cell wall structure integrity, however, it was not able to preserve the cell shape. The fast freezing process not only promoted the formation of very fine ice crystals but also preserved the morphology of the cells. The NMR analytical parameters, texture and drip loss showed limitations to differentiate the different freezing protocols. . None of the freezing protocols preserved the colour parameters of the fresh potato.

\section{Benchmarking of freeze damage assessment methods for vegetables on the basis of efficiency, accuracy, cost-of operation, and ease of operation}

In this section, freeze damage assessment methods used during this study were evaluated based on various benchmarking parameters and a decision table (dedicated to benchmarking study) was proposed. Table 3 summarizes the results obtained within this study. Pros and cons 
related to the different methods considered in this study for assessing the freeze damage in potato were discussed.. These observations would provide useful information about the analytical techniques that can be used to estimate freeze damage efficiently.

The focused freeze damage assessment technologies like CLSM, and global freeze damage assessment techniques like texture analysis (also includes laser-puff texture analysis), low field NMR relaxometry, and colour analysis tests used in this study was found to be relevant methods to distinguish the fresh samples from frozen/thawed sample.

The acquired results suggest that cryo-SEM and CLSM are suitable for validating minor quality changes among the different freezing protocols. Meanwhile, the global methods such as texture, NMR, and drip loss can only reflect larger quality changes.

In order to compare freezing protocols, colour analysis was found to be an unsuitable parameter.

Efficiency and accuracy wise, cryo-SEM and CLSM can be termed as best methods to analyze the freezing injuries.

NMR, cryo-SEM and CLSM techniques are expensive techniques, whereas texture analysis, drip loss measurements, colour analysis are cost-effective technologies. The analyses time for NMR is long, while other methods take substantially less time.

From a global point of view, a debate could be opened on which is the most relevant technique to assess freeze damage. Two key parameters can be tackled, (i) the size of the field that is embraced by the technique and (ii) the representative size of the technique. For example, NMR will tackle a sample of $\mathrm{ca} 1 \mathrm{~cm}$ and will provide information at the level of a water molecule $(2.75 \AA$ A). Cryo-SEM will look at field of ca $100 \mu \mathrm{m}$ with information at nanometer scale, even though in this case the freeze damage is observed at the scale of an ice crystal ( $\operatorname{circa} 10 \mu \mathrm{m})$. The ratio between the size of field and the representative size of technique could be considered as a kind of "freeze damage assessment index" (FDA Index) to assess the relevance of each technique. The higher the FDA index will be, the useful will be (a priori) the technique. From such point of view NMR looks like the best candidate, even though the interpretation and quantification of the freeze damage based on $T_{1}$ and $T_{2}$ values are not very well documented in the literature and still remain quite subjective. The major concerns relates to the size of the field. Observation of the freeze damage on a single cell can be very informative and detailed, but ca a hundred of cell should be analyzed to obtain an 
638 averaged information, which is out of reach for time reasons. Another aspect relies on the 639 possibility to repeat the analysis and on the time needed for a single measurement. CLSM and 640 Cryo-SEM bring informative images that can help to visualize the defaults and that can 641 support observations done with other techniques at a broader field like NMR, texture, drip

642 losses. The precision of the analytical method is one of the most important factors when choosing the 643 methods for freeze damage assessment. A method that imparts minimum error to the measured result 644 will help in better understanding of the impact of process conditions on the sample. Based on the error 645 calculations made for the quantitative methods (Table 3), the drip loss measurement seemed to be 646 more satisfactory, followed by colour analysis, hardness analysis, deformation analysis by the laser647 puff tester, NMR analysis and Young's Modulus analysis. Overall, the error imparted by the 648 analytical techniques were quite low in values.

649 The proper assessment of freeze damage remains a challenge and requires a mass of 650 experimental work before drawing any conclusion. However, this comparative study is maybe 651 the first one that proposes a benchmarking of so many different analytical techniques often 652 considered to assess the freeze damage.

\section{Acknowledgements:}

654 This work received financial support from the French National Research Agency (ANR) and 655 the Swedish Research Council FORMAS under the FREEZEWAVE project (SUSFOOD656 ERANET, FR: ANR-14-SUSF-0001, SE: 2014-1925). We would like to thank Anthony Ogé 657 (ONIRIS) for designing the laser-puff firmness tester. A special thanks to McCain food for 658 supplying potatoes required for the experimentation. The authors would also like to thank 659 Romain Mallet (Univ-Angers - SCIAM) for their assistance in cryo-SEM imaging 660 respectively. 
663

664

665

666

667

668

669

670

671

672

673

674

675

676

677

678

679

680

681

682

683

684

685

686

687

688

689

690

691

692

693

694

695

696

697

698

699

700

701

702

703

704

705

706

707

708

709

710

Alvarez, M. D., Canet, W., \& López, M. E. (2002). Influence of deformation rate and degree of compression on textural parameters of potato and apple tissues in texture profile analysis. European Food Research and Technology, 215, 13-20.

Anon (2018). http://cobra.rdsor.ro/cursuri/cielab.pdf. Retrieved on $3^{\text {rd }}$ July 2018.

Barbosa-Cánovas, G. V., Altunakar, B., \& Mejía-Lorío, D. J. (2005). Introduction to freezing. Freezing of fruits and vegetables: An agribusiness alternative for rural and semi-rural areas (Vol. 158, pp. 1-36). Rome: Food \& Agriculture Organization.

Bevilacqua, A., Zaritzky, N. E., \& Calvelo, A. (1979). Histological measurements of ice in frozen beef. Journal of Food Technology, 14, 237-251.

Bomben, J. L., \& King, C. J. (1982). Heat and mass transport in the freezing of apple tissue. J. Fd Technol., 17, 615-632.

Bourne, M. C. (1968). Texture Profile of Ripening Pears. Journal of Food Science, 33, 223226.

Cano, M. P. (1996). Vegetables. In L. E. Jeremiah (Ed.), Freezing effects on food quality (pp. 247-298). New York: Marcel Dekker.Inc.

Cao, X., Zhang, F., Zhao, D., Zhu, D., \& Li, J. (2018). Effects of freezing conditions on quality changes in blueberries. Journal of the Science of Food and Agriculture, 98, 46734679.

Charoenrein, S., \& Owcharoen, K. (2016). Effect of freezing rates and freeze-thaw cycles on the texture, microstructure and pectic substances of mango. International Food Research Journal, 23, 613-620.

Chassagne-berces, S., Fonseca, F., Citeau, M., \& Marin, M. (2010). Freezing protocol effect on quality properties of fruit tissue according to the fruit, the variety and the stage of maturity. LWT - Food Science and Technology, 43, 1441-1449.

Chassagne-Berces, S., Poirier, C., Devaux, M. F., Fonseca, F., Lahaye, M., Pigorini, G., Girault, C., Marin, M., \& Guillon, F. (2009). Changes in texture, cellular structure and cell wall composition in apple tissue as a result of freezing. Food Research International, 42, 788-797.

Chevalier, D., Le Bail, a., \& Ghoul, M. (2000). Freezing and ice crystals formed in a cylindrical food model: Part II. Comparison between freezing at atmospheric pressure and pressure-shift freezing. Journal of Food Engineering, 46, 287-293.

Delgado, A. E., \& Sun, D. W. (2001). Heat and mass transfer models for predicting freezing processes - a review. Journal of Food Engineering, 47, 157-174.

Fennema, O. (1966). An over-all view of low temperature food preservation. Cryobiology, 3(3), 197-213.

Foucat, L., \& Lahaye, M. (2014). Short communication A subzero ${ }^{1} \mathrm{H}$ NMR relaxation investigation of water dynamics in tomato pericarp. Food Chemistry Journal, 158, 278282.

Fuchigami, M., Hyakumoto, N., \& Miyazaki, K. (1995). Programmed Freezing Affects Texture, Pectic Composition and Electron Microscopic Structures of Carrots. Journal of Food Science, 60, 137-141.

Gao, D., \& Critser, J. K. (2000). Mechanisms of Cryoinjury in Living Cells. ILAR Journal, 41, 187-196.

Hung, Y. C., McWatters, K. H., \& Prussia, S. E. (1998). Peach Sorting Performance of Anondestructive Laser Air-Puff Firmness Detector. Applied Engineering in Agriculture, 14, 513-516.

Jahncke, M., Baker, R. C., \& Regenstein, J. M. (1992). Frozen storage of unwashed cod (Gadus morhua) frame mince with and without kidney tissue. Journal of Food Science, 
57, 575-580.

Jha, P. K., Xanthakis, E., Chevallier, S., Jury, V., \& Le-Bail, A. (2018). Assessment of freeze damage in fruits and vegetables. Food Research International. In press, accepted article.

Khan, A. A., \& Vincent, J. F. V. (1993). Compressive Stiffness and Fracture Properties of Apple and Potato Parenchyma. Journal of Texture Studies, 24, 423-435.

Khan, A. A., \& Vincent, J. F. V. (1996). Mechanical damage induced by controlled freezing in apple and potato. Journal of Texture Studies, 27, 143-157.

Koch, H., Seyderhelm, I., Wille, P., Kalichevsky, M. T., \& Knorr, D. (1996). Pressure-shift freezing and its influence on texture, colour, microstructure and rehydration behaviour of potato cubes. Nahrung, 40, 125-131.

Lahaye, M., Falourd, X., Limami, A. M., \& Foucat, L. (2015). Water mobility and microstructure evolution in the germinating medicago truncatula seed studied by NMR relaxometry. A revisited interpretation of multicomponent relaxation. Journal of Agricultural and Food Chemistry, 63, 1698-1710.

Li, B., \& Sun, D. W. (2002). Effect of power ultrasound on freezing rate during immersion freezing of potatoes. Journal of Food Engineering, 55, 277-282.

Lovelock, J. E. (1957). The denaturation of lipid-protein complexes as a cause of damage by freezing. Proceedings of the Royal Society of London. Series B, Biological Sciences, 147, 427-433.

Luyts, A., Wilderjans, E., Waterschoot, J., Haesendonck, I. Van, Brijs, K., Courtin, C. M., Hills, B., \& Delcour, J. A. (2013). Low resolution 1H NMR assignment of proton populations in pound cake and its polymeric ingredients. Food Chemistry, 139, 120-128.

Mazur, P. (1977). The role of intracellular freezing in the death of cells cooled at supraoptimal rates. Cryobiology, 14, 251-272.

Mazur, P. (1984). Freezing of living cells: mechanisms and implications. American Journal of Physiology-Cell Physiology, 247, C125-142.

McGlone, V. A., \& Jordan, R. B. (2000). Kiwifruit and apricot firmness measurement by the non-contact laser air-puff method. Postharvest Biology and Technology, 19, 47-54.

Orlowska, M., Havet, M., \& Le-Bail, A. (2009). Controlled ice nucleation under high voltage DC electrostatic field conditions. Food Research International, 42, 879-884.

Penny, I. F. (1975). Use of a centrifuging method to measure the drip of pork Longissimus dorsi slices before and after freezing and thawing. Journal of the Science of Food and Agriculture, 26, 1593-1602.

Phinney, D. M., Frelka, J. C., Wickramasinghe, A., \& Heldman, D. R. (2017). Effect of Freezing Rate and Microwave Thawing on Texture and Microstructural Properties of Potato (Solanum tuberosum). Journal of Food Science, 82, 933-938.

Prussia, S. E., Astleford, J. J., Hewlett, B., \& Hung, Y. C. (1994). 5,372,030. U.S. Patent and Trademark Office.

Reid, D. S. (1997). Overview of physical/chemical aspects of freezing. In M. C. Erickson \& Y.-C. Hung (Eds.), Quality in frozen food (pp. 10-28). Dordrecht: Springer Science+Business Media.

Rutledge, D. N., Rene, F., Hills, B. P., \& Foucat, L. (1994). Magnetic resonance imaging studies of the freeze-drying kinetics of potato. Journal of Food Process Engineering, 17, $325-352$.

Sadot, M., Curet, S., Rouaud, O., Le-bail, A., \& Havet, M. (2017). Numerical modelling of an innovative microwave assisted freezing process. International Journal of Refrigeration, 80, 66-76.

Shi, X., Datta, A. K., \& Mukherjee, Y. (1998). Thermal Stresses From Large Volumetric Expansion During Freezing of Biomaterials. Transactions of the ASME, 120, 720-726.

Shi, X., Datta, A. K., \& Mukherjee, Y. (1999). Thermal fracture in a biomaterial during rapid 
freezing. Journal of Thermal Stresses, 22, 275-292.

Shi, X., Datta, A. K., \& Throop, J. A. (1998). Mechanical Property Changes during Freezing of a Biomaterial. Transactions of the ASAE, 41, 1407-1414. to Food Engineering (4th ed., pp. 501-541). San Diego: Academic Press publications.

Sirijariyawat, A., Charoenrein, S., \& Barrett, D. M. (2012). Texture improvement of fresh and frozen mangoes with pectin methylesterase and calcium infusion. Journal of the Science of Food and Agriculture, 92, 2581-2586.

Van Buggenhout, S., Lille, M., Messagie, I., Von Loey, A., Autio, K., \& Hendrickx, M. (2006). Impact of pretreatment and freezing conditions on the microstructure of frozen carrots: Quantification and relation to texture loss. European Food Research and Technology, 222, 543-553.

Van Buggenhout, S., Messagie, I., Maes, V., Duvetter, T., Loey, A. Van, \& Hendrickx, M. (2006). Minimizing texture loss of frozen strawberries: effect of infusion with pectinmethylesterase and calcium combined with different freezing conditions and effect of subsequent storage / thawing conditions. European Food Research and Technology, 223, 395-404.

Zhang, Y., Zhao, J. H., Ding, Y., Xiao, H. W., Sablani, S. S., Nie, Y., Wu, S.-J., \& Tang, X. M. (2018). Changes in the vitamin C content of mango with water state and ice crystals under state/phase transitions during frozen storage. Journal of Food Engineering, 222, 49-53. 


\section{Captions for the Figures}

Figure 1: Load-strain curve providing detail about the firmness of the potato during the compression tests.

Figure 2: Laser-puff firmness testing prototype.

Figure 3: A representative deformation curve obtained while performing the laser puff test. Conversion of volts to $\mathrm{mm}: 1 \mathrm{~V}=2 \mathrm{~mm}$.

Figure 4: Illustration of sample preparation step prior to imaging in cryo-SEM.

Figure 5: Protocol followed for CLSM imaging of unblanched potato.

Figure 6: Representative freezing curves of potatoes under different freezing methods.

Figure 7: (a) Deformation curve obtained for fresh and frozen-thawed samples (conversion of volts to $\mathrm{mm}: 1 \mathrm{~V}=2 \mathrm{~mm}$ ) and (b) deformation values (in $\mathrm{mm}$ ) for fresh and frozen-thawed potatoes (under different freezing rates) acquired using laser-puff firmness tester. SF (slow freezing at $-18{ }^{\circ} \mathrm{C}$ ), IF (intermediate freezing at $-30{ }^{\circ} \mathrm{C}$ ) and $\mathrm{FF}$ (fast freezing at $-74{ }^{\circ} \mathrm{C}$ ).

811 Figure 10: Effect of different freezing conditions on the drip loss of potato.

812 Figure 11: Effect of freezing protocols on color parameters $\left(a-L^{*}\right.$ value or Lightness, $b-a^{*}$ 813 value or Redness, $c-b^{*}$ value or Yellowness and $d-\Delta E$ ) of potato. Mean values of 9

Figure 8: Distributions of relaxation peak components ((a) $T_{2}^{*}$ and (b) $T_{2}$ ) at $-20{ }^{\circ} \mathrm{C}$ of potato samples frozen by various freezing protocols: slow freezing at $-18{ }^{\circ} \mathrm{C}$ (red lines), intermediate freezing at $-30{ }^{\circ} \mathrm{C}$ (blue lines), and fast freezing at $-74{ }^{\circ} \mathrm{C}$ (black lines). (The $\mathrm{x}$-axis correspond to the relaxation times expressed in $\mathrm{ms}$ (milliseconds).

Figure 9: $T_{2}$ relaxation peak data of frozen-thawed potatoes at $4{ }^{\circ} \mathrm{C}$ : (a) fresh sample, (b) after freezing at $-18{ }^{\circ} \mathrm{C}$ (c) after freezing at $-30{ }^{\circ} \mathrm{C}$ and (d) after freezing at $-74{ }^{\circ} \mathrm{C}$.

\section{repetitions are represented with confidence interval.}

Figure 12: Microstructure of potato before and after freezing under the different freezing protocols. $(a, b)$ environmental SEM images of the fresh cell showing the cellular structure and starch granules imbedded into it. Cryo-SEM after freezing at $-18{ }^{\circ} \mathrm{C}-\mathrm{SF}(\mathrm{c}, \mathrm{d})$, at -30 ${ }^{\circ} \mathrm{C}$-IF $(\mathrm{e}, \mathrm{f})$ and at $-74{ }^{\circ} \mathrm{C}$-FF $(\mathrm{g}, \mathrm{h})$, respectively. White colored arrows in images are pointing the cells containing ice crystals. Red arrow showing the area where the breakdown of cell structure happened. Orange arrows indicate the cells that might have transformed from polyhedral to almost round shape. Other abbreviations in the picture are A: air space; S: starch granule; $\mathrm{W}$ : cell wall structure.

Figure 13: Microstructure evaluation using CLSM: (a) fresh potato, (b) frozen-thawed after freezing at $-18{ }^{\circ} \mathrm{C}-\mathrm{SF}$, (c) at $-30{ }^{\circ} \mathrm{C}$-IF and (d) at $-74{ }^{\circ} \mathrm{C}$-FF. Other abbreviations in the picture are $\mathrm{S}$ : starch granule, $\mathrm{W}$ : cell wall, $\mathrm{S}_{\mathrm{p}}$ is probably the gap created when of cell moved apart from each other as a consequence of freezing-thawing. The red arrows indicating the deformed, distorted and shrunk cells. Orange arrows indicating loss of regularity of the cell 
830 walls compared to fresh and FF samples. Yellow arrows showing the folded and buckled cell 831 wall structure formed due to SF process.

832

833 Figure 14: Microstructure evaluation using CLSM: (a) single cell of fresh potato, (b) single 834 potato cell (imaged in frozen state) after freezing at $-18{ }^{\circ} \mathrm{C}$ (SF), (c) frozen-thawed potato 835 structure after frozen at $-30{ }^{\circ} \mathrm{C}$ (IF) and (d) frozen-thawed potato structure after frozen at $836-74{ }^{\circ} \mathrm{C}(\mathrm{FF})(\mathrm{d}) . \mathrm{S}_{\mathrm{p}}$ is probably the gap between the cells created due to freezing-thawing 837 process. Black arrow showing a part of broken cell wall. White arrow indicating discontinuity 838 in the cell wall structure. Red arrow evince the deformed cell with irregular cell wall structure 839 (orange arrows).

840

841

842

843

844

845

846

847

848

849 


\section{Captions for Tables}

851 Table 1. Effects of different freezing protocols on the freezing properties of potatoes.

852 Table 2. Textural parameters measured for potatoes under different freezing conditions.

853 Table 3. Benchmarking study on freeze damage assessment methods.

854

855

856

857

858

859

860

861

862

863

864

865

866

867

868

869

870

871

872

873

874

875

876

877

878

879 
880 Table 1. Effects of different freezing protocols on the freezing properties of potatoes.

\begin{tabular}{ccccc}
\hline $\begin{array}{c}\text { Freezing } \\
\text { condition }\end{array}$ & $\begin{array}{c}\text { Initial freezing } \\
\text { point }\left({ }^{\circ} \mathbf{C}\right)\end{array}$ & $\begin{array}{c}\text { Characteristic } \\
\text { freezing time }(\mathbf{m i n})\end{array}$ & $\begin{array}{c}\text { Overall freezing } \\
\text { time }(\mathbf{m i n})\end{array}$ & $\begin{array}{c}\text { Overall freezing } \\
\text { rate }\left({ }^{\circ} \mathbf{C} / \mathbf{m i n}\right)\end{array}$ \\
\hline$-18{ }^{\circ} \mathrm{C}(\mathrm{SF})$ & $-0.3 \pm 0.14$ & $29.12 \pm 3.94$ & $72.30 \pm 0.14$ & $0.48 \pm 0.00$ \\
$-30^{\circ} \mathrm{C}(\mathrm{IF})$ & $-0.73 \pm 0.06$ & $17.18 \pm 0.79$ & $26.31 \pm 0.62$ & $1.36 \pm 0.05$ \\
$-74{ }^{\circ} \mathrm{C}(\mathrm{FF})$ & n.d. & $8.52 \pm 1.53$ & $14.51 \pm 1.49$ & $2.51 \pm 0.25$ \\
\hline
\end{tabular}

881

882 
883 Table 2. Textural parameters measured for potatoes under different freezing conditions.

\begin{tabular}{lcc}
\hline Parameters & Hardness (N) & Young's modulus (MPa) \\
\hline Fresh & $190 \pm 19^{\mathrm{a}}$ & $5.46 \pm 0.44^{\mathrm{a}}$ \\
SF $\left(\right.$ at $\left.-18{ }^{\circ} \mathrm{C}\right)$ & $47 \pm 11^{\mathrm{c}}$ & $1.37 \pm 0.33^{\mathrm{c}}$ \\
IF $\left(\right.$ at $\left.-30{ }^{\circ} \mathrm{C}\right)$ & $68 \pm 16^{\mathrm{b}, \mathrm{c}}$ & $2.09 \pm 0.41^{\mathrm{b}, \mathrm{c}}$ \\
FF $\left(\right.$ at $\left.-74^{\circ} \mathrm{C}\right)$ & $90 \pm 8^{\mathrm{b}}$ & $2.60 \pm 0.45^{\mathrm{b}}$ \\
\hline
\end{tabular}

884

885

886

887

888

889

890

891

892

893

894

895

896

897

898

899

900

901

902

903 
Table 3. Benchmarking study on freeze damage assessment methods.

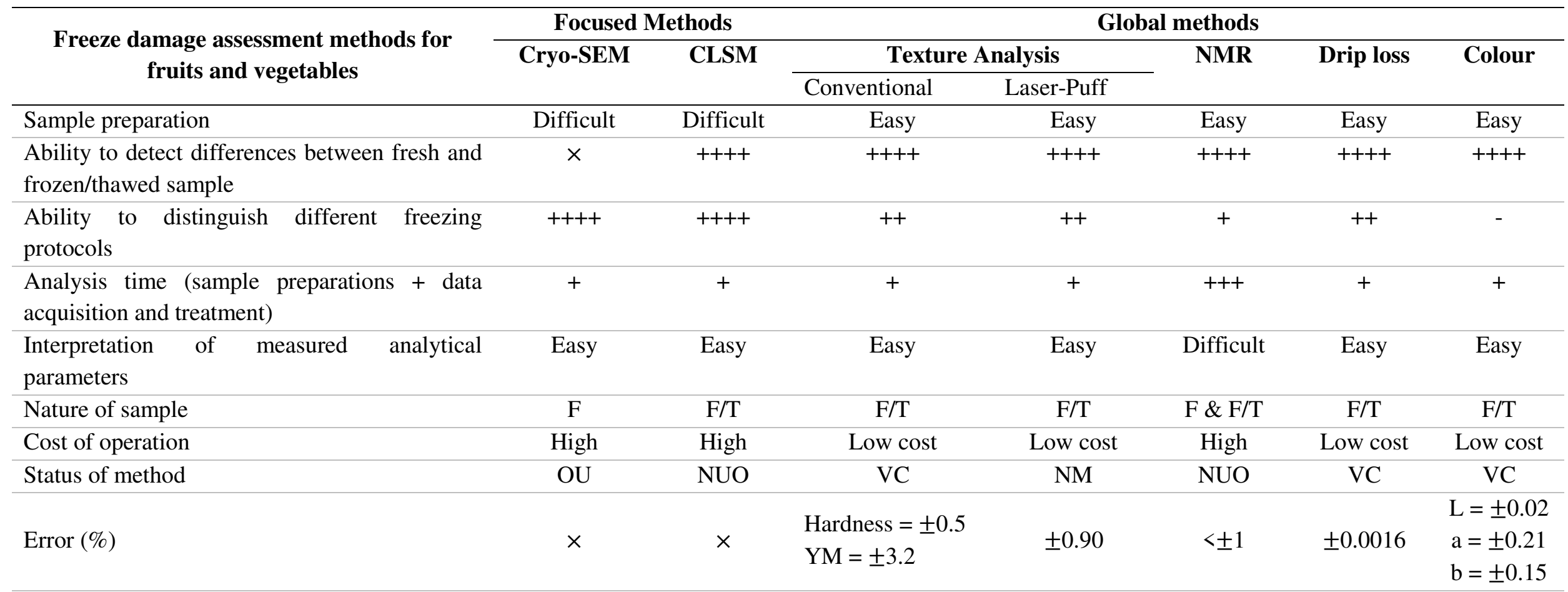

$+=$ Lowest value $++++=$ Highest value; $\times=$ Not applicable; $-=$ No effect.

Abbreviations of the words: F = Frozen; F/T = Frozen/Thawed; FD = Freeze dried; OU = Often used; NUO = Not used often; VC = Very common; NM = New method; $\mathrm{YM}=$ Young's Modulus.

$\mathrm{L}, \mathrm{a}, \mathrm{b}$ are different colour parameters. 


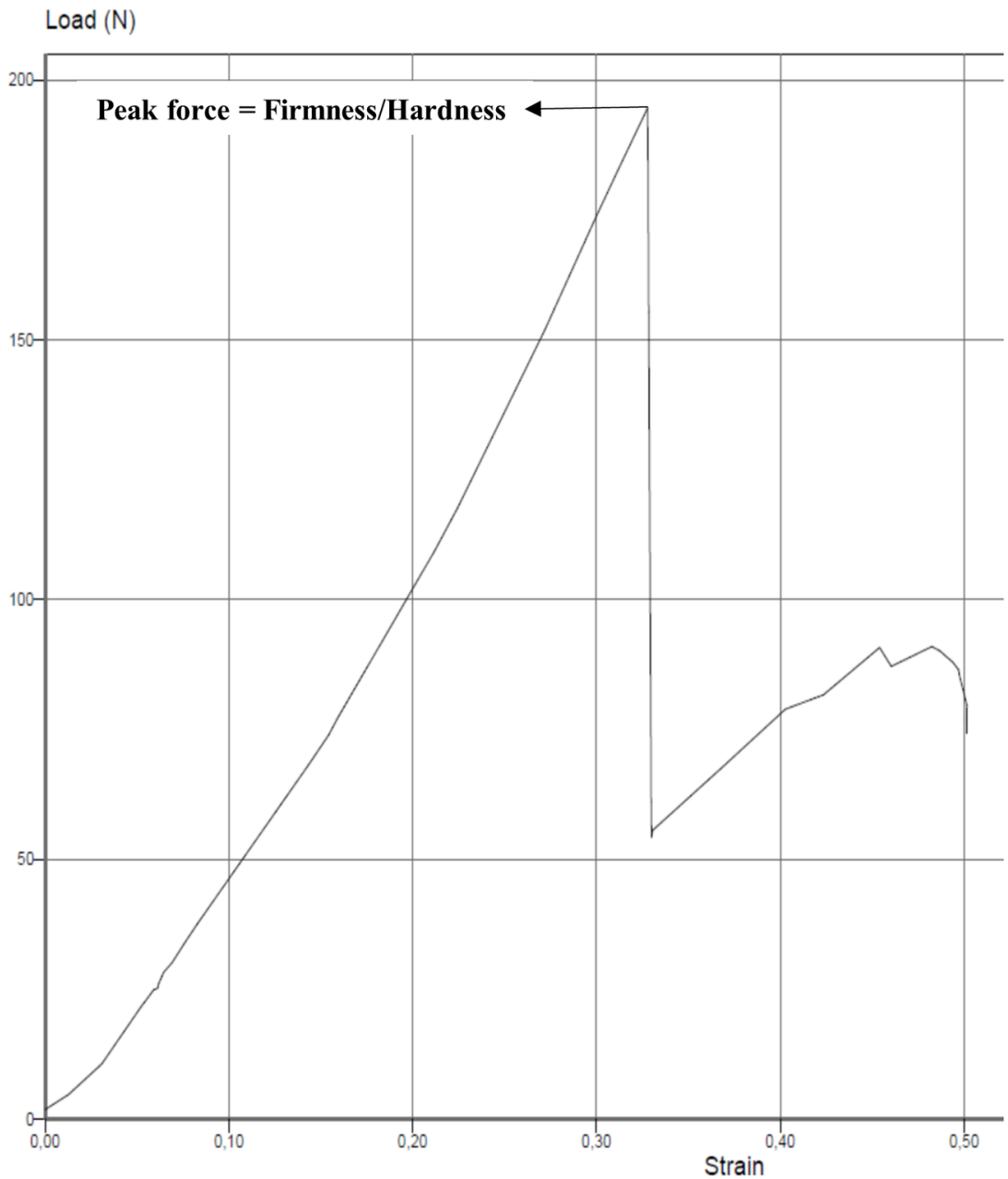




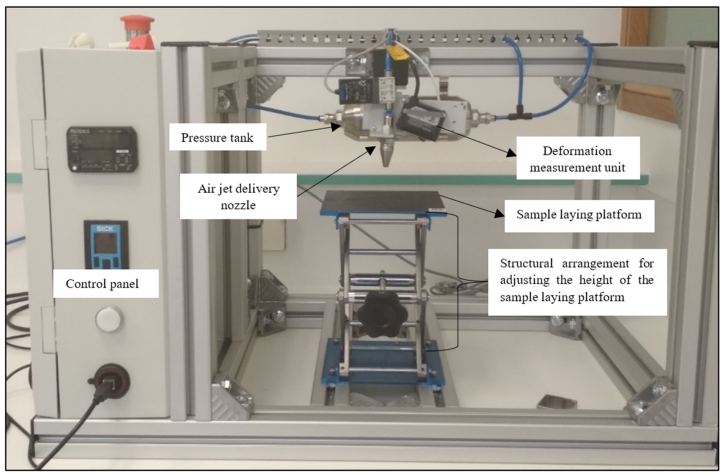




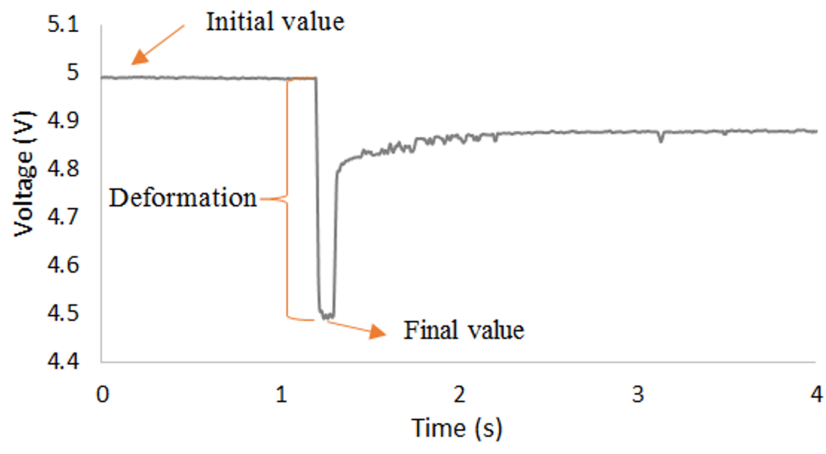




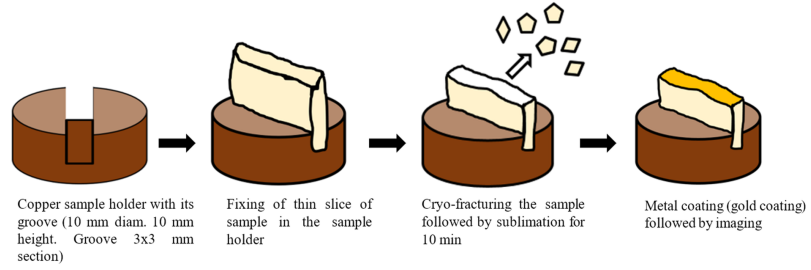


Sampling

Cylindrical shape $($ diameter $(\emptyset)=8 \mathrm{~mm} \&$ height $(\mathrm{H})=5 \mathrm{~mm})$; weight $=0.25 \mathrm{~g}$

$\downarrow$

Sample was stained in Acridine Orange $(0.01 \%)(\mathrm{pH} 7.2)$ for 2 hours at $4{ }^{\circ} \mathrm{C}$

$\downarrow$

Freezing under different conditions (at $-18^{\circ} \mathrm{C},-30^{\circ} \mathrm{C}$ and $-74^{\circ} \mathrm{C}$ )

$\downarrow$

Thawing of sample at room temperature, followed by slicing using a microtome ( $80 \mu \mathrm{m}$ slice was used for imaging study).

$\downarrow$

CLSM imaging was then performed using different resolution objective lenses (for e.g. $20 \mathrm{X}, 10 \mathrm{X}, 4 \mathrm{X}$, etc.)
Staining the sample

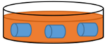

Preparation for imaging

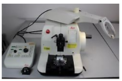

Confocal Laser Scanning Microscope

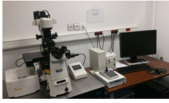




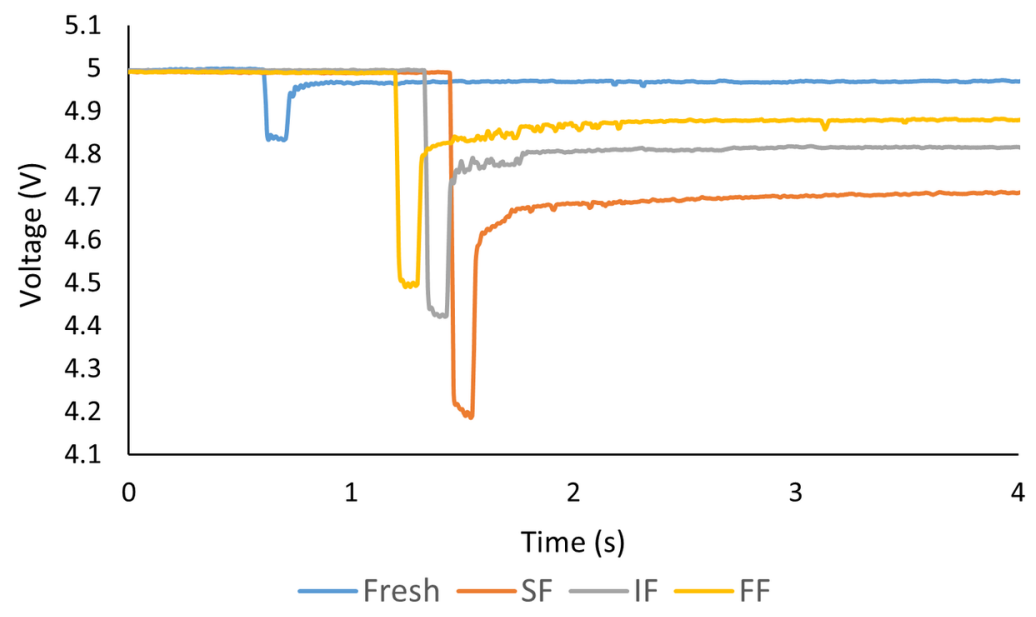

(a)

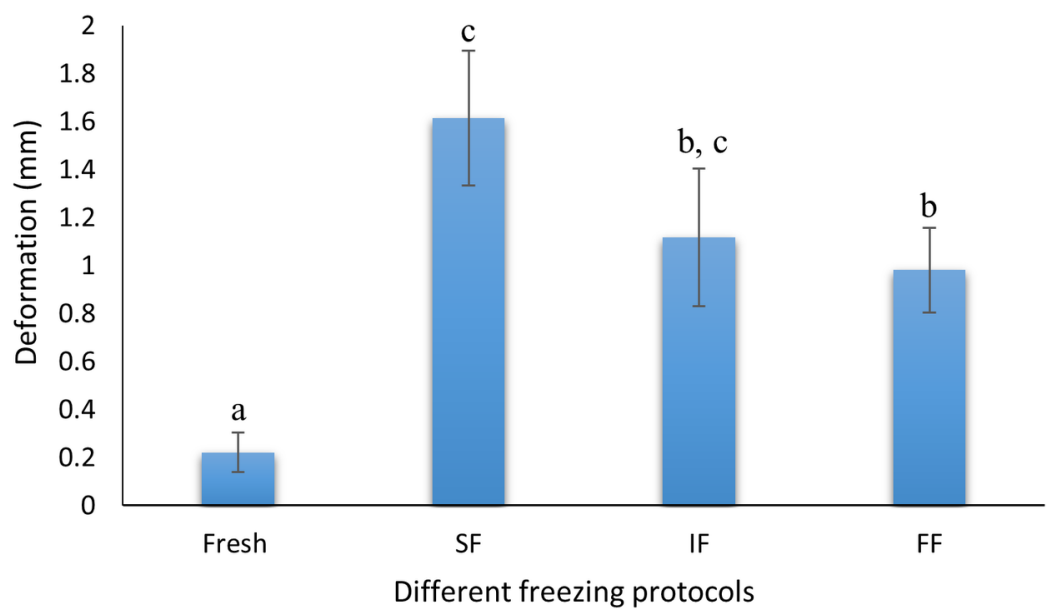

(b) 

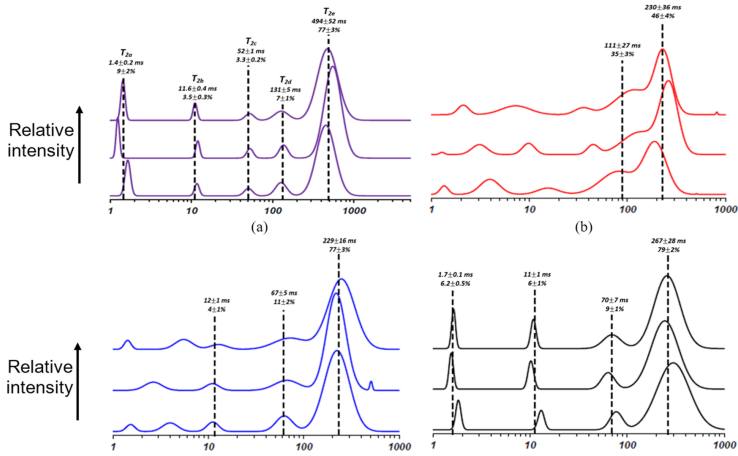

(c)

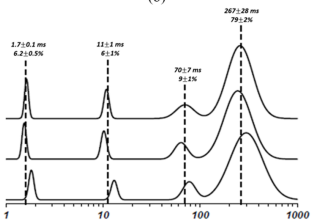

(d) 


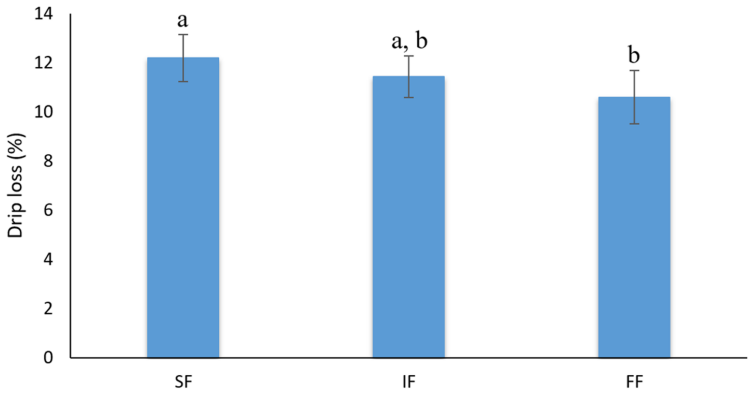




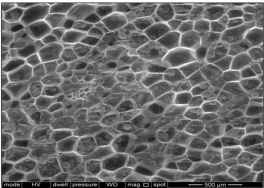

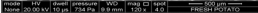

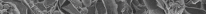

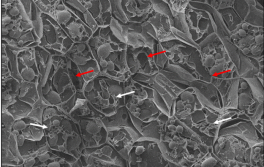

\begin{tabular}{|c|c|c|c|c|}
\hline 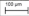 & 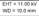 & 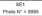 & 1000 & 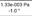 \\
\hline
\end{tabular}

(c)

(a)

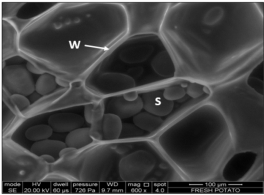

(b)

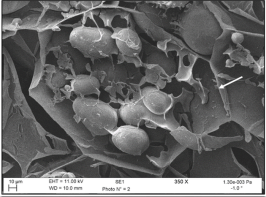

(d)

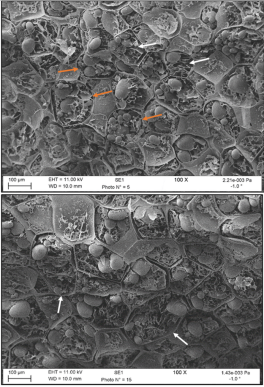

(e)

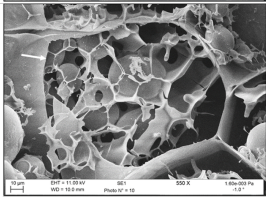

(f)

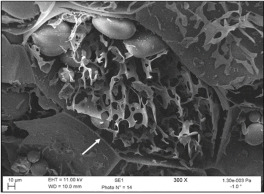

(h) 


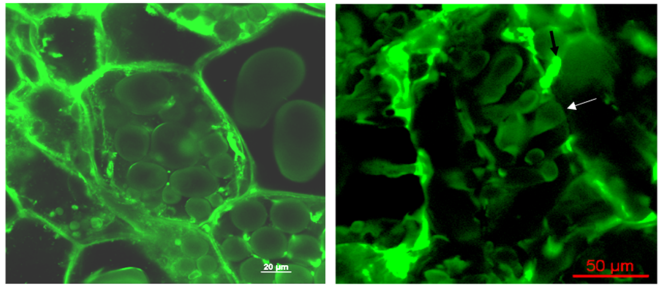

(a)

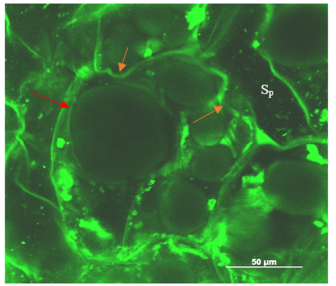

(b)

(c)

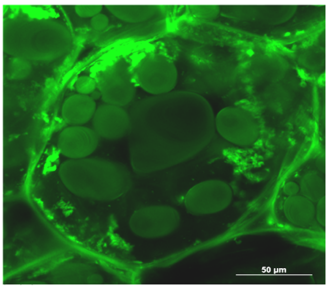

(d) 